\title{
Effects of sulfur dioxide on hypoxic pulmonary vascular structural remodeling
}

\author{
Yan Sun ${ }^{1}$, Yue Tian ${ }^{1}$, Mainali Prabha', Die Liu', Stella Chen², Rongyuan Zhang ${ }^{1}$, Xueqin Liu', Chaoshu Tang ${ }^{3,4}$, \\ Xiuying Tang ${ }^{5}$, Hongfang $\operatorname{Jin}^{1}$ and Junbao Du ${ }^{1,4}$
}

Hypoxic pulmonary hypertension is a pathophysiological process important in the development of various cardiopulmonary diseases. Recently, we found that sulfur dioxide could be produced endogenously by pulmonary vessels, and that it showed vascular regulatory capabilities. In this paper, we examined the role of sulfur dioxide in hypoxic pulmonary vascular structural remodeling (HPVSR). A total of 48 Wistar rats were divided into six groups. Rats in the hypoxic group, hypoxic + sulfur dioxide group, and hypoxic + hydroxamate group were left under hypoxic conditions, whereas the control group, control + sulfur dioxide group, and control + hydroxamate group rats were left in room air. For each group, we measured the pulmonary arterial pressure, sulfur dioxide content in plasma and lung tissue, glutamate oxaloacetate transaminase 1 and 2 mRNAs, micro- and ultra-structural changes in pulmonary arteries, proliferation of pulmonary smooth muscle cells, vascular collagen metabolism, pulmonary endothelial cell inflammatory response, and pulmonary vascular endothelin-1 production in the rats. In hypoxic rats, the content of sulfur dioxide in plasma and lung tissue decreased significantly in comparison with those in the control groups, and significant pulmonary hypertension, pulmonary vascular structural remodeling, and increased vascular inflammatory response were also observed in hypoxic rats. Sulfur dioxide donor significantly downregulated Raf-1, mitogen-activated protein kinase kinase-1 (MEK-1) and p-ERK/ERK, and inhibited pulmonary vascular smooth muscle cell proliferation, collagen remodeling and pulmonary vascular endothelial cell nuclear factor- $\kappa \mathrm{B}$ (NF- $\kappa \mathrm{B})$, and intercellular adhesion molecule 1 (ICAM-1) expressions. It also prevented pulmonary hypertension and pulmonary vascular structural remodeling in association with the upregulated sulfur dioxide/glutamate oxaloacetate transaminase pathway. Hydroxamate, however, advanced pulmonary hypertension, pulmonary vascular structural remodeling, and inflammatory response of the pulmonary artery in association with a downregulated sulfur dioxide/glutamate oxaloacetate transaminase pathway. The results suggested that sulfur dioxide markedly inhibited Raf-1, MEK-1, and the phosphorylation of extracellular signal-regulated kinase (ERK), and then inhibited pulmonary arterial smooth muscle cell (PASMC) proliferation induced by hypoxia. The downregulated sulfur dioxide/glutamate oxaloacetate transaminase pathway may be involved in the mechanisms responsible for pulmonary hypertension and pulmonary vascular structural remodeling.

Laboratory Investigation (2010) 90, 68-82; doi:10.1038/labinvest.2009.102; published online 12 October 2009

KEYWORDS: glutamate oxaloacetate transaminase; inflammation; proliferation; pulmonary hypertension; sulfur dioxide; vasoacive peptides

Hypoxic pulmonary hypertension is an important pathophysiological process in the development of various cardiopulmonary diseases. Hypoxic pulmonary vascular structural remodeling (HPVSR) is considered to be the key pathological basis of hypoxic pulmonary hypertension. Excess accumula- tion of the extracellular matrix (ECM) in the wall of small pulmonary muscularized arteries, as well as increased proliferation of pulmonary arterial smooth muscle cells (PASMCs), is the main pathological process of HPVSR, the pathogenesis of which is not completely understood.

\footnotetext{
${ }^{1}$ Department of Pediatrics, Peking University First Hospital, Beijing, China; ${ }^{2}$ University of California, San Diego, La Jolla, CA, USA; ${ }^{3}$ Institute of Cardiovascular Diseases, Peking University First Hospital, Beijing, China; ${ }^{4}$ Key Laboratory of Molecular Cardiology, Ministry of Education, Beijing, China and ${ }^{5}$ Laboratory of Electronic Microscope, Peking University First Hospital, Beijing, China

Correspondence: Professor J Du, MD, Department of Pediatrics, Peking University First Hospital, Xi-An Men Street No. 1, West District, Beijing 100034, China.

E-mail: junbaodu1@126.com and

Dr H Jin, PhD, Department of Pediatrics, Peking University First Hospital, Xi-An Men Street No. 1, West District, Beijing 100034 , China.

E-mail: jinhongfang51@126.com
}

Received 3 March 2009; revised 16 August 2009; accepted 24 August 2009 
In the 1980s, nitric oxide (NO) and carbon monoxide (CO) were determined to be gaseous messenger molecules sharing common features such as low molecular weight, continuous release, and quick dispersal and absorbance. ${ }^{1-4}$ It was recently suggested that hydrogen sulfide $\left(\mathrm{H}_{2} \mathrm{~S}\right)$ is a novel gasotransmitter. ${ }^{5,6}$ Although the gasotransmitters were found to be capable of relaxing vessels and interfering with vascular structural remodeling, ${ }^{7-9}$ the possible mechanisms responsible for regulation of PASMC proliferation in pulmonary structural remodeling induced by hypoxia are unclear.

Although sulfur dioxide $\left(\mathrm{SO}_{2}\right)$ is a toxic gas, it can be produced endogenously in vivo from sulfur-containing amino acids. L-cysteine is first oxidized to L-cysteinesulfinate by cysteine dioxygenase. L-cysteinesulfinate can develop through transamination by glutamate-oxaloacetate transaminase (GOT) into $\beta$-sulfinylpyruvate, which decomposes spontaneously to pyruvate and $\mathrm{SO}_{2}$. The latter is further metabolized to form sulfite in vivo, oxidized by sulfite oxidase to sulfate, and excreted in urine. ${ }^{10,11} \mathrm{~L}$-cysteinesulfinate may be decarboxylated by cysteinesulfinate decarboxylase to $\mathrm{CO}_{2}$ and hypotaurine. Most of the hypotaurine is subsequently oxidized to taurine (Figure 1). Our research group first discovered that $\mathrm{SO}_{2}$ could be produced endogenously by pulmonary vessels, could regulate vascular activities, and was involved in the inflammatory response; these features suggest that endogenous $\mathrm{SO}_{2}$ may be associated with the development of cardiovascular diseases. ${ }^{12-14}$

Is endogenous $\mathrm{SO}_{2}$ involved in HPVSR pathogenesis? If so, what are the possible mechanisms by which $\mathrm{SO}_{2}$ has a role in

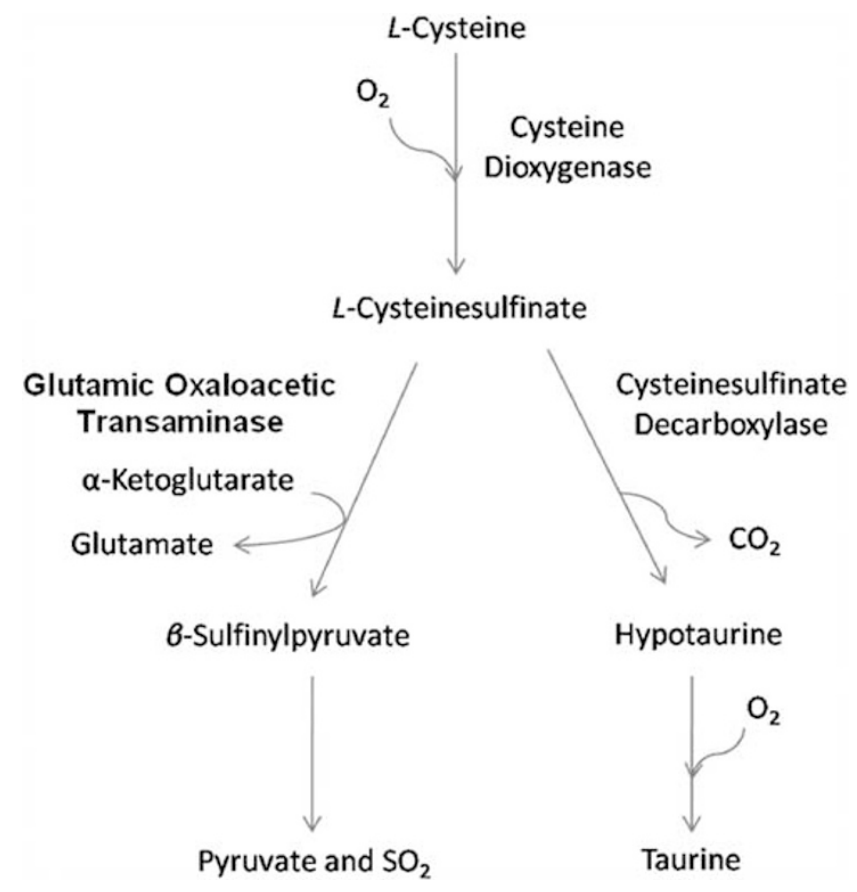

Figure 1 Metabolic pathways of cysteine to $\mathrm{SO}_{2}$ and its derivatives. $\mathrm{SO}_{2}$ : sulfur dioxide. the development of hypoxic pulmonary hypertension? The present study was designed to analyze changes in the production of endogenous $\mathrm{SO}_{2}$ during HPVSR development, and its possible role in the pathogenesis of HPVSR.

\section{MATERIALS AND METHODS Preparation of the Animal Model}

The study protocol was approved by the animal research committee of Peking University (Beijing, China). Forty-eight male Wistar rats $(150-160 \mathrm{~g})$ in the hypoxic group $(n=8)$, hypoxic $+\mathrm{SO}_{2}$ group $(n=8)$, and hypoxic $+\mathrm{HDX}$ (hydroxamate) group $(n=8)$ were exposed to hypoxic conditions for 21 days $(6 \mathrm{~h} /$ day $)$, as described by Zhang. ${ }^{15}$ Rats in the control group $(n=8)$, control $+\mathrm{SO}_{2}$ group $(n=8)$, and control + HDX group $(n=8)$ were housed in identical cages adjacent to the hypoxic chamber in which rats breathed room air. Hypoxia was generated by infusing nitrogen gas into the chamber. The degree of hypoxia was maintained by balancing nitrogen infusion and air that leaked inwardly through holes in the chamber. The partial pressure of oxygen $\left(\mathrm{PO}_{2}\right)$ in rats of the normoxic group was $80.68 \pm 4.2 \mathrm{~mm} \mathrm{Hg}$ and the partial pressure of carbon dioxide $\left(\mathrm{PCO}_{2}\right)$ was $38.76 \pm 7.9 \mathrm{~mm} \mathrm{Hg}$. In the hypoxic group, $\mathrm{PO}_{2}$ was $41.96 \pm 3.4 \mathrm{~mm} \mathrm{Hg}$ and $\mathrm{PCO}_{2}$ was $26.36 \pm 3.0 \mathrm{~mm} \mathrm{Hg}$. For rats in the control $+\mathrm{SO}_{2}$ group and hypoxic $+\mathrm{SO}_{2}$ group, $\mathrm{Na}_{2} \mathrm{SO}_{3} / \mathrm{NaHSO}_{3}$ was dissolved in physiological $(0.9 \%)$ saline at $0.54 \mathrm{mmol} / \mathrm{kg} ; 0.18 \mathrm{mmol} / \mathrm{kg}$ body weight was injected ${ }^{16}$ (i.p.) before hypoxia every day. HDX, an inhibitor of the enzyme responsible for endogenous generation of $\mathrm{SO}_{2}$, was injected (i.p.) at a dose of $3.7 \mathrm{mg} / \mathrm{kg}$ into the rats in the hypoxic + HDX group every day before hypoxia. The same dosage of HDX was injected (i.p.) into rats of the control + HDX group. An identical volume of physiological saline was injected into rats of the control group and hypoxic group.

\section{Measurement of Pulmonary Arterial Pressure (PAP)}

At 3 weeks after hypoxic exposure, rats were anesthetized with urethane $(1 \mathrm{~g} / \mathrm{kg}$ body weight, i.p.). A silicone catheter (outer diameter, $0.9 \mathrm{~mm}$ ) was introduced into the right jugular vein through venotomy. It was passed across the tricuspid valve and right ventricle into the pulmonary artery. The other end of the catheter was linked to a Multi-Lead Physiological Monitor (BL-420F, Chengdu TME Technology, Chengdu, China) through a P50 pressure transducer. The curves of PAP were traced, and PAP measured.

\section{Preparation and Morphometric Analysis of Lung Tissue} After PAP was measured, the thoracic cavity was opened. One side of the lung lobe was removed, fixed in $10 \%$ (wt/vol) formalin, and processed into $5-\mu \mathrm{m}$ paraffin sections for evaluation using in situ hybridization and immunohistochemistry. Small, medium, and large arteries were defined as 15-50, 50-150, and $>150 \mu \mathrm{m}$ in external diameter, respectively. 
The external diameter of pulmonary arteries was as follows. For small pulmonary arteries, it was $38 \pm 4,43 \pm 4$, $39 \pm 1,44 \pm 3,41 \pm 4$, and $43 \pm 2 \mu \mathrm{m}$ in control, control $+\mathrm{SO}_{2}$, control $+\mathrm{HDX}$, hypoxic group, hypoxic $+\mathrm{SO}_{2}$, and hypoxic $+\mathrm{HDX}$ groups, respectively $(P>0.05)$. For medium-sized pulmonary arteries, it was $78 \pm 8,87 \pm 11$, $80 \pm 7,85 \pm 12,80 \pm 14$, and $97 \pm 14 \mu \mathrm{m}$ in control, control $+\mathrm{SO}_{2}$, control $+\mathrm{HDX}$, hypoxic group, hypoxic $+\mathrm{SO}_{2}$, and hypoxic + HDX groups, respectively $(P>0.05)$. For large pulmonary arteries, it was $168 \pm 12,180 \pm 14,180 \pm 27$, $170 \pm 10, \quad 169 \pm 14$, and $174 \pm 14 \mu \mathrm{m}$ in control, control $+\mathrm{SO}_{2}$, control $+\mathrm{HDX}$, hypoxic group, hypoxic $+\mathrm{SO}_{2}$, and hypoxic + HDX groups, respectively $(P>0.05)$. All small pulmonary arteries per tissue section were assessed at $\times 400$ magnification. Each vessel was divided into three types according to the degree of muscularization: muscularized arteries (MA, with two distinct elastic lamina, external and internal), partially muscularized arteries (PMA, with a continuous external elastic lamina and a discontinuous internal elastic lamina), and non-muscularized arteries (NMA, with only one single elastic lamina). The percentage of each type was determined.

\section{Preparation for Ultra-Structural Analysis of Lung Tissues}

The remaining blood in the right lung was rinsed with saline through the pulmonary artery. Meanwhile, 4\% polyoxymethylene was slowly infused through the trachea into the lung under $20 \mathrm{~cm} \mathrm{H}_{2} \mathrm{O}$ pressure until the lung surface became smooth and expanded. Approximately 5 min later, the right lower lung was re-sected and rapidly fixed in polyoxymethylene solution. Samples were paraffin embedded in the standard manner, sliced into $5-\mu \mathrm{m}$ serial sections, and stained using hematoxylin and eosin (H\&E). We preliminarily observed the remodeling of lung tissues and the pulmonary vasculature under light microscopy.

The right middle lung was isolated and rapidly fixed in 3\% glutaraldehyde solution. It was then post-fixed with $1 \%$ perosmic acid, dehydrated with an acetone gradient, and embedded with Epon 812. The ultra-thin sections were double stained with uranyl acetate and lead citrate, and observed using a transmission electron microscope (TEM; JEM 1230, JEOL Ltd, Tokyo, Japan).

\section{Determination of the Content of $\mathrm{SO}_{2}$ in Plasma and Lung Tissue}

$\mathrm{SO}_{2}$ concentrations were measured using high-performance liquid chromatography (HPLC, Agilent 1100 series, Agilent Technologies, Palo Alto, CA, USA). In brief, samples of plasma and tissue homogenate $(100 \mu \mathrm{l})$ were mixed with $70 \mu \mathrm{l}$ of $0.212 \mathrm{mM}$ sodium borohyderide in $0.05 \mathrm{M}$ Tris- $\mathrm{HCl}(\mathrm{pH}$ 8.5 ) and incubated at room temperature for $30 \mathrm{~min}$. Samples were then mixed with $10 \mu \mathrm{l}$ of $70 \mathrm{mM}$ monobromobimane in acetonitrile. After incubation for $10 \mathrm{~min}$ at $42^{\circ} \mathrm{C}, 50 \mu \mathrm{l}$ of $1.5 \mathrm{M}$ perchloric acid were added to the mixture, followed by vortex mixing. Protein precipitates were removed by centrifugation at $12400 \mathrm{~g}$ for $10 \mathrm{~min}$ at room temperature. The supernatant was immediately neutralized by adding $20 \mu \mathrm{l}$ of $2.0 \mathrm{M}$ Tris, and then gently mixed and centrifuged again at $12400 \mathrm{~g}$ for $10 \mathrm{~min}$. The neutralized supernatant (about $100 \mu \mathrm{l})$ was transferred to a sampler vial, stored at $4^{\circ} \mathrm{C}$ in foilwrapped tubes, and $5 \mu \mathrm{l}$ of the supernatant was injected onto the HPLC column (Agilent 1100 series, Agilent Technologies, Palo Alto, CA, USA). Samples were resolved on a $4.6 \mathrm{~mm} \times 150 \mathrm{~mm} \mathrm{C18}$ column.

The column was equilibrated with methanol, acetic acid, and water in the ratio 5.00:0.25:94.75 (by volume, $\mathrm{pH} 3.4$ ). It was developed with a gradient of methanol at a flow rate of $1 \mathrm{ml} / \mathrm{min}$ as follows: $0-8 \mathrm{~min}, 5 \%$; $8-15 \mathrm{~min}, 5-12 \%$; 15-20 min, $12 \%$; 20-30 min, $12-20 \%$; $30-32 \mathrm{~min}, \quad 20 \%$; 32-35 min, 20-100\%; 35-40 min, $100 \%$; 40-43 min, $100-5 \%$; and $43-45 \mathrm{~min}, 5 \%$. Sulfite-bimane adduct was prepared as a calibrator, and was detected by excitation at $392 \mathrm{~nm}$ and emission at $479 \mathrm{~nm}^{17}$

\section{Determination of GOT Activity in Lung Tissue}

GOT activity in lung tissues was determined using Synchron DXC 800 (Beckman Coulter Inc, Fullerton, CA, USA). The lung tissues of rats were homogenated with $0.01 \mathrm{~mol} / \mathrm{l}$ phosphate-buffered saline (PBS; weight:volume, 1:10). Protein precipitates were removed by centrifugation at $2500 \mathrm{~g}$ for $10 \mathrm{~min}$ at room temperature. The supernatant was used to detect GOT content by the Reitman method and tissue protein was measured by the Coomassie method.

\section{Measurement of the Expression of GOT1 and GOT2, Pre- Collagen I and III, and Aortic Endothelin-1 (ET-1) mRNAs in Lung Tissue Using Quantitative Real-Time Polymerase Chain Reaction (PCR)}

Total RNA in tissue was extracted using Trizol reagent (Gibco $\mathrm{BRL}$ ), and reverse transcribed using oligo $\mathrm{d}(\mathrm{T})_{18}$ primer and M-MLV reverse transcriptase. Primers and TaqMan probes for the quantification of cDNAs in samples were designed with the software Primer Express 3.0 (Applied Biosystems, Foster City, CA, USA). The primers and probes were synthesized by SBS Company, Limited (Beijing, China). Quantitative real-time PCR was carried out using an ABI PRISM 7300 instrument (Applied Biosystems). The sequence of the primers and probes is shown in Table 1.

The PCR condition was pre-denatured at $95^{\circ} \mathrm{C}$ for $5 \mathrm{~min}$, $95^{\circ} \mathrm{C}$ for $15 \mathrm{~s}$, and $60^{\circ} \mathrm{C}$ for $1 \mathrm{~min}$ for 40 cycles. The amount of $\beta$-actin cDNA in the sample was used to calibrate the amount of sample needed for determination.

\section{Measurement of the Expression of Proliferating Cell Nuclear Antigen (PCNA), Nuclear Factor Kappa B (NF- $\kappa$ B) and Intercellular Adhesion Molecule 1 (ICAM-1) in Lung Tissue Using Immunohistochemical Analysis}

After being dewaxed by dimethylbenzene, sections of lung tissue were put into distilled water. They were then processed by $3 \% \mathrm{H}_{2} \mathrm{O}_{2}$ for $12 \mathrm{~min}$. The slides were washed three times 
Table 1 The sequence of the primers and probes of glutamate oxaloacetate transaminase1 (GOT1), GOT2, pre-collagen I and pre-collagen III, endothelin-1 (ET-1), and $\beta$-actin

\section{GOT1}

$\begin{array}{ll}\text { Forward primer } & \text { GOT1-F: 5'-CCAGGGAGCTCGGATCGT-3' } \\ \text { Reverse primer } & \text { GOT1-R: 5'-GCCATTGTCTTCACGTTCCTT-3' } \\ \text { Probe } & \text { GOT1-P: 5'-CCACCACCCTCTCCAACCCTGA-3' }\end{array}$

GOT2

Forward primer

Reverse primer

Probe

Pre-collagen I

Forward primer

Pre-collagen I-F: 5'-CTTGTTGCTGAGGGCAACAG-3'

Reverse primer

Probe

Pre-collagen I-R : 5'-GCAGGCGAGATGGCTTATTC-3'

Pre-collagen I-P: 5'-AGATTCACCTACACTGTCCTTG

TCGATGGC-3'

$\begin{array}{ll}\text { Pre-collagen III } & \\ \text { Forward primer } & \text { Pre-collagen III-F: 5'-GAAAAAACCCTGCTCGGAATT-3' } \\ \text { Reverse primer } & \text { Pre-collagen III-R: 5'-AGAGACCTGAAATTCTGCCACC } \\ & \text { CTGAACTC-3' } \\ \text { Probe } & \text { Pre-collagen III-P: 5'-ATCCATCTTGCAGCCTTGGT-3' }\end{array}$

ET-1

Forward primer

Reverse primer

Probe

ET-F: 5'-AGCTGGTGGAGGGAAGAAAAC-3'

ET-R: 5'-GTTCCGCTITCAACTITGCAA-3'

ET-P: 5'-TTGGAGGCCATCAGCAACAGCATC-3'

\begin{abstract}
$\beta$-actin
Forward primer

Reverse primer

Probe

$\beta$-Actin-F: 5'-ACCCGCGAGTACAACCTTCTT-3'

$\beta$-Actin-R: 5'-TATCGTCATCCATGGCGAACT-3'

$\beta$-Actin-P: 5'-CCTCCGTCGCCGGTCCACAC-3'
\end{abstract}

with PBS (each for $5 \mathrm{~min}$ ). Antigens were exposed for $15 \mathrm{~min}$, and the slides were rinsed again. Samples were blocked for 30 min with goat serum working fluid. Polyclonal antibody was added to PCNA, NF- $\kappa$ B, and ICAM-1 (1:100, 1:50, and 1:50, respectively), and the mixture incubated at $4^{\circ} \mathrm{C}$ overnight. Slides were thrice rinsed with PBS ( 5 min each). Biotinylated anti-mouse IgG was incubated for $60 \mathrm{~min}$ at $37^{\circ} \mathrm{C}$. After the slides were rinsed in PBS thrice, horseradish peroxidase (HRP) streptavidin was added for $30 \mathrm{~min}$ at $37^{\circ} \mathrm{C}$. Slides were thrice rinsed in PBS ( $5 \mathrm{~min}$ each). Then $3,3^{\prime}-$ diaminobenzidine (DAB) was added to develop color, and the sections were stained with hematoxylin. After the sections were dehydrated through a graded ethanol series and made transparent in dimethylbenzene, they were mounted. The brown granules in pulmonary smooth muscle cells (PSMCs) and endothelial cells under light microscopy were defined as positive signals. For negative controls, sections were processed as above, with the exception that primary incubation was performed with non-immune goat serum instead of primary antibodies. PCNA and NF- $\kappa \mathrm{B}$ were defined using the semiquantitative method as detailed above. The proliferation index (PI) was calculated according to the percentage of smooth muscle cells expressing PCNA of all smooth muscle cells in a pulmonary artery. The expression of NF- $\kappa \mathrm{B}$ and ICAM-1 in endothelial cells was calculated as the ratio of positive cells to total cells.

\section{Measurement of the cDNA of Matrix Metalloproteinase-13 (MMP-13) and Tissue Inhibitors of Metalloproteinease-1 (TIMP-1) in Lung Tissue by In Situ Hybridization}

Digoxigenin (DIG)-labeled MMP-13 and TIMP-1 cDNA were used as probes for in situ hybridization.

The sequence of MMP-13 is as follows:

(1) 5'-GTATTCACCCACATCAGGCACTCCACATC- ${ }^{\prime}$

(2) $5^{\prime}$-CCAGGAGGAAAAGCGTGTGCCAGAAGAC- $3^{\prime}$

(3) 5'-GGATAGGGCTGGGTCACACTTCTCTGGT-3';

The sequence of TIMP-1 is as follows:

(1) 5'-CCAGAAATCATCGAGACCACCTTATACCAGCGTT- $3^{\prime}$

(2) $5^{\prime}$-CCAGACCACCTTATACCAGCGTTATGAGA- ${ }^{\prime}$

(3) 5'-CAGTGTTTCCCTGTTTATCTATCCCTTGC-3'.

Omission of a cDNA probe on previously confirmed positive tissue sections was used as the negative control process in this study. The liver sections from tissues of hepatic cancer were used as the positive control process in this study. The expression of the percentage of positive cells in the endothelium was calculated as the ratio of positive cells to total cells.

The Amount of Collagen I and III in Lung Tissue Using Enzyme-Linked Immunosorbent Assay (ELISA)

Levels of collagen I and III in lung tissue were detected using ELISA. The lower lobes of the right lung were homogenized and centrifuged at $3000 \mathrm{~g}$. The liquid supernatants were obtained as homogenates for testing the concentrations of collagen I and III. Collagen I and III were assayed using a double-antibody sandwich ELISA according to the manufacturer's instructions (Rapidbio, CA, USA). In brief, the samples $(100 \mu \mathrm{l})$, collagen I standards $(2000,1000,500,250$, $125,62.5,31.25$, and $0 \mathrm{pg} / \mathrm{ml}$ ), and collagen III standards $(144,72,36,18,9,4.5,2.25$, and $0 \mathrm{ng} / \mathrm{ml})$ were added to the wells. Each was tested in duplicate. After 1-h incubation at $37^{\circ} \mathrm{C}$, samples were removed and the plates were washed with a washing buffer (consisting of PBS, $10 \mathrm{mmol} / 1 \mathrm{pH} 7.4$ and Tween-20, $0.1 \%$ ), soaked for a few minutes, and washed again five times. Blot plates were dried by being gently tapped upside-down on filter paper. Anti-rat collagen I and III (50 $\mu \mathrm{l})$ were added to each of the plates' wells and left for 
$60 \mathrm{~min}$ at $37^{\circ} \mathrm{C}$. After five additional washing steps, $100 \mu \mathrm{l}$ HRP was added to the wells and left for $60 \mathrm{~min}$ at $37^{\circ} \mathrm{C}$. The plates were washed five times, and $100 \mu \mathrm{l}$ of tetramethylbenzidine (TMB) substrate was added to each well and shaken gently for $10 \mathrm{~s}$. The mixture was incubated in the dark for 5-10 min at room temperature. The optical density (OD) at $492 \mathrm{~nm}$ was measured using an ELISA reader (Bio-Rad, Richmond, CA, USA) after stopping the reaction by adding $100 \mu \mathrm{l}$ of stop solution to each well. The standard curve of OD values $v s$ concentrations of collagen I and III was obtained. Sample data were plotted on the standard curve and the concentrations of collagen I and III in the sample were obtained. The standard curve was created by reducing the data using computer software capable of generating a fourparameter logistic (4-PL) curve fit. Data were linearized by plotting the log of the concentrations of collagen I and III $v s$ the $\log$ of the OD. The best-fit line was determined using regression analysis.

\section{Measurement of Expression of Extracellular Signal- Regulated Kinases (ERK) and the Phosphorylation of ERK (p-ERK), Raf-1, and MEK-1 in Lung Tissue Using Western Blotting}

Rat lung tissues were homogenized and lysed. Equal amounts of proteins were boiled and separated using sodium dodecylpolyacrylamide gel electrophoresis (SDS-PAGE), and transferred using electorphoresis to a nitrocellulose membrane. The primary antibody dilutions were 1:1000 for ERK, 1:200 for p-ERK, Raf-1, and mitogen-activated protein kinase kinase 1 (MEK-1) antibody (Santa Cruz), and 1:10000 for $\beta$-actin (Labvision). Secondary antibodies (Santa Cruz) were used at a dilution of 1:10000. Immunoreactions were visualized using electrochemiluminescence (ECL) and exposed to X-ray film (Kodak Scientific).

\section{Data Analysis}

Data are expressed as means \pm s.d. For comparison of differences among the three groups, one-way ANOVA followed by a post hoc analysis (least-square difference test) was performed using SPSS 13.0 statistical analysis software. To compare the difference between two groups, the independent-sample $t$-test was used. $P<0.05$ was considered significant.

\section{RESULTS}

\section{Mean Pulmonary Artery Pressure (PAP)}

There was no statistical significance in the mean PAP of the control $+\mathrm{SO}_{2}$ group compared with the control group $(P>0.05)$. Compared with the control group, mean PAP of the control + HDX group was increased significantly $(P<0.01)$. Compared with the control group, the mean PAP of the hypoxic group was raised significantly $(P<0.01)$. However, compared with the hypoxic group, the mean $\mathrm{PAP}$ of the hypoxic $+\mathrm{SO}_{2}$ group was low $(P<0.05)$, but
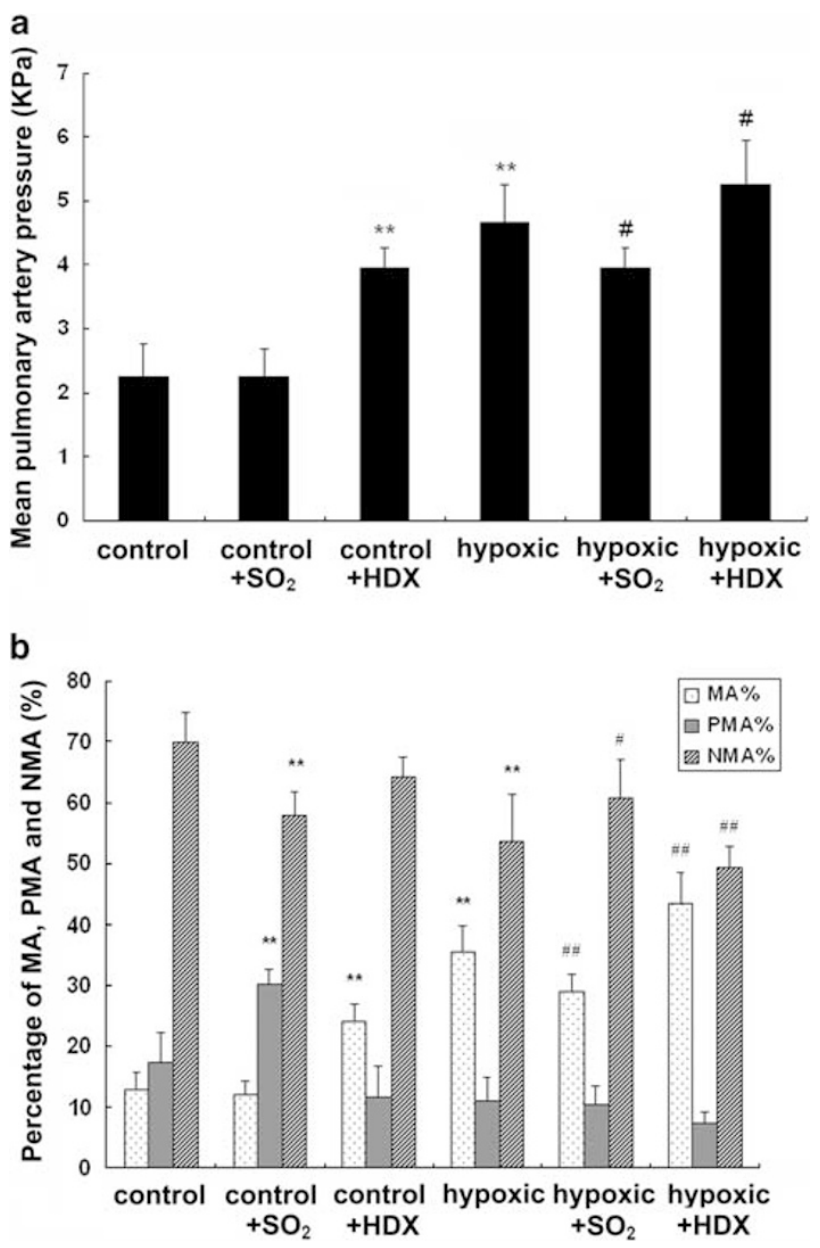

Figure 2 Mean pulmonary artery pressure (mean \pm s.d., $\mathrm{mm} \mathrm{Hg}$ ) (a) and percentage of muscularized arteries (MA), partially muscularized arteries (PMA), and non-muscularized arteries (NMA) (mean \pm s.d., \%) in small pulmonary vessels (b) of rats in the six groups. ${ }^{* *}$ Compared with the control group $P<0.01$; ${ }^{\prime}$ compared with the hypoxic group, $P<0.05$; \#\#compared with the hypoxic group, $P<0.01$.

was clearly raised in the hypoxic + HDX group $(P<0.05)$ (Figure 2).

\section{Percentage of Muscularized Arteries (MA), Partially Muscularized Arteries (PMA), and Non-Muscularized Arteries (NMA)}

In the control $+\mathrm{SO}_{2}$ group, the percentage of $\mathrm{MA}$ in pulmonary arteries did not change when compared with the control group $(P>0.05)$, but clearly rose in the control + HDX group when compared with the MA percentage in pulmonary arteries in control rats $(P<0.01)$. In hypoxic rats, the percentage of MA in pulmonary arteries significantly rose compared with the control rats $(P<0.01)$. However, when compared with the hypoxic group, the percentage of MA in pulmonary arteries significantly decreased in the hypoxic $+\mathrm{SO}_{2}$ group $(P<0.01)$. When treated with $\mathrm{HDX}$, hypoxic rats showed an increased percentage of MA in 

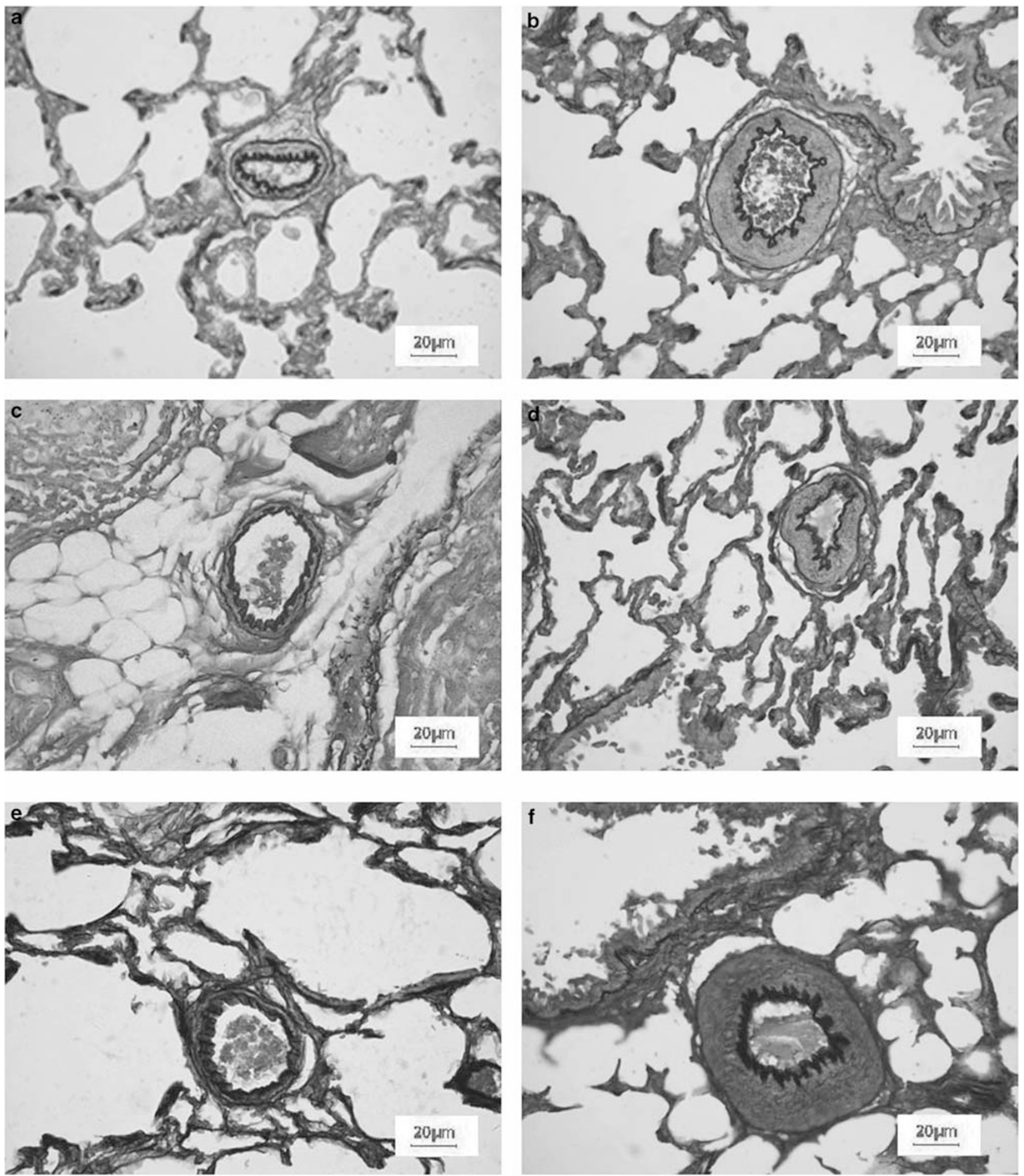

Figure 3 The level of muscularization in small pulmonary arteries among the six groups (Hart's $\times 400)$. (a) In the control group, the thickness of the inner elastic layer was even, and the structure of smooth muscle cells was normal. (b) In hypoxic rats, the inner elastic layers were uneven. The medial layer was hypertrophic. (c) In the control $+\mathrm{SO}_{2}$ group, the inner elastic layer was comparatively even. The structure of smooth muscle cells was normal. (d) In the control + HDX group, the inner elastic layers were uneven. The medial layer was significantly hypertrophic. (e) In the hypoxic $+\mathrm{SO}_{2}$ group, the inner elastic layer was comparatively even. The medial layer was much thinner than that of the hypoxic group. (f) In the hypoxic + HDX group, the inner elastic layer was obviously uneven. The medial layer was hypertrophic compared with the hypoxic group. HDX: hydroxamate. 
pulmonary arteries in comparison to those without HDX treatment $(P<0.01$; Figures 2 and 3$)$.

In contrast with the control group, the percentage of NMA in rats in the control $+\mathrm{SO}_{2}$ group did not change $(P>0.05)$. However, it did decrease in the control + HDX group when compared with the control rats $(P<0.05)$. When compared with the control group, the percentage of NMA in rats in the hypoxic group decreased significantly $(P<0.01)$, whereas when compared with the hypoxic group, it rose significantly in the hypoxic $+\mathrm{SO}_{2}$ group $(P<0.05)$ and the hypoxic + HDX group $(P<0.01$; Figures 2 and 3$)$.

The percentage of PMA obviously increased in the control $+\mathrm{SO}_{2}$ group, but it was not statistically different $(P>0.05$; Figures 2 and 3 ) among the rats of the other five groups.

\section{Ultra-Structural Changes in Pulmonary Arteries}

In the pulmonary arteries of rats in the control group, the vascular endothelial cells were flat and thin, the inner elastic layer thickness was even, and smooth muscle cells had a fusiform shape. The structure of actin filaments showed a dense body and the dense patches were clear. Similar findings were noted in the control $+\mathrm{SO}_{2}$ group. When compared with the control group, the vascular endothelial cells in the control + HDX group were augmented and slightly degenerated, and lumens were narrowed. In hypoxic rats, the vascular endothelial cells were augmented and slightly degenerated; small vacuoles could be observed, and lumens were narrowed. The inner elastic layers were discontinuous and the thickness was uneven. The smooth muscle cells were hypertrophic, and cell organs were abundant. In the control $+\mathrm{SO}_{2}$ group, the inner elastic layer was comparatively even. The structure of smooth muscle cells was normal. In the control + HDX group, the inner elastic layers were uneven. The medial layer was significantly hypertrophic. In the hypoxic $+\mathrm{SO}_{2}$ group, the inner elastic layer was comparatively even. Smooth muscle cells had a fusiform shape, and the structure of the dense body and dense patch was clear. With hypoxic + HDX treatment, vascular endothelial cells were augmented and seriously degenerated, small vacuoles were observed, and lumens were much narrower. The inner elastic layers had undergone rarefaction, and had uneven thickness. The smooth muscle cells were hypertrophic, and cell organs were abundant (Figure 4).

\section{$\mathrm{SO}_{2}$ Content in Plasma and Lung Tissue}

$\mathrm{SO}_{2}$ content in the plasma of rats in the hypoxic group was lower than that of the control rats $(P<0.05)$, but rose significantly $(P<0.05)$ in the hypoxic $+\mathrm{SO}_{2}$ group compared with the hypoxic group. After $\mathrm{HDX}$ treatment, the $\mathrm{SO}_{2}$ content in plasma decreased significantly $(P<0.05)$ in hypoxic rats (Figure 5).

There were significant differences among the four groups in $\mathrm{SO}_{2}$ content in lung tissues. It decreased significantly in rats of the hypoxic group when compared with the control group $(P<0.05)$. Compared with the hypoxic group, the $\mathrm{SO}_{2}$ content in the lung tissues in the hypoxic $+\mathrm{SO}_{2}$ group rose significantly $(P<0.01)$, but it decreased markedly $(P<0.01)$ in the hypoxic + HDX group (Figure 5).

\section{Expression of GOT1 and GOT2 mRNAs in Lung Tissue}

Under hypoxia, rats showed reduced expressions of GOT1 and GOT2 mRNAs in lung tissue as compared with control rats (both $P<0.01$ ). $\mathrm{SO}_{2}$ donor did not alter the expression of GOT1 and GOT2 mRNAs in the lung tissue of hypoxic rats (both $P>0.05$ ). In the hypoxic + HDX group, the expressions of GOT1 and GOT2 mRNAs were significantly upregulated in comparison with those of the hypoxic group (both $P<0.01$; Figure 5).

\section{GOT Activity in Lung Tissue}

Compared with the control group, GOT activity of the hypoxic group decreased significantly $(P<0.01)$. In comparison with the hypoxic group, GOT activity showed no difference in the hypoxic $+\mathrm{SO}_{2}$ group $(P<0.05)$, but it decreased in the hypoxic + HDX group $(P<0.01$; Figure 6$)$.

\section{Proliferation Index of Pulmonary Artery Smooth Muscle Cells}

Compared with the control group, the PI of PSMCs in rats of the hypoxic group rose significantly in small pulmonary arteries $(P<0.01)$, medium-sized arteries $(P<0.01)$, and large arteries $(P<0.01)$. The PI of PSMCs in rats of the control $+\mathrm{SO}_{2}$ group did not change $(P>0.05)$, but increased obviously in the small pulmonary arteries $(P<0.01)$, medium-sized arteries $(P<0.01)$, and large arteries $(P<0.01)$ of the rats in the control + HDX group. The PI decreased

Figure 4 Electronic micrographs of small pulmonary arteries in the six groups $(12000 \mathrm{~g})$. (a) In the pulmonary artery of rats in the control group, the vascular endothelial cells were flat and thin, the thickness of the inner elastic layer was even, and smooth muscle cells had a fusiform shape. The structure of actin filaments involved a dense body and the dense patch was clear. (b) In hypoxic rats, vascular endothelial cells were augmented and slightly degenerated, small vacuoles could be observed, and lumens were narrowed. The inner elastic layers were discontinuous and thickness was uneven. The smooth muscle cells were hypertrophic, and cell organs were abundant. (c) In control $+\mathrm{SO}_{2}$ group, the thickness of the inner elastic layer was gently uneven, and smooth muscle cells had a fusiform shape. The structure of actin filaments involved a dense body and the dense patch was clear. (d) In control + HDX group, the vascular endothelial cells were augmented, and small vacuoles could be obviously observed. The inner elastic layers were discontinuous and thickness was uneven. The smooth muscle cells were hypertrophic markedly. (e) In the hypoxic $+\mathrm{SO}_{2}$ group, the inner elastic layer was comparatively even. Smooth muscle cells had a fusiform shape, and structure of the dense body and dense patch was clear. (f) With hypoxic and HDX treatment, vascular endothelial cells were augmented and seriously degenerated, small vacuoles were observed, and lumens were much narrower. The inner elastic layers were discontinuous and thickness was uneven. Smooth muscle cells were hypertrophic, and cell organs were abundant. HDX: hydroxamate; $\mathrm{SO}_{2}$ : sulfur dioxide; SMC: smooth muscle cell; EC: endothelial cell; EL: elastic layer. 
significantly in the small arteries $(P<0.01)$, medium-sized arteries $(P<0.01)$, and large arteries $(P<0.01)$ of rats in the hypoxic $+\mathrm{SO}_{2}$ group when compared with the hypoxic rats.
HDX treatment clearly increased the PI of PSMCs in small arteries $(P<0.05)$, medium-sized arteries $(P<0.01)$, and large arteries $(P<0.05)$ of hypoxic rats (Table 2$)$.
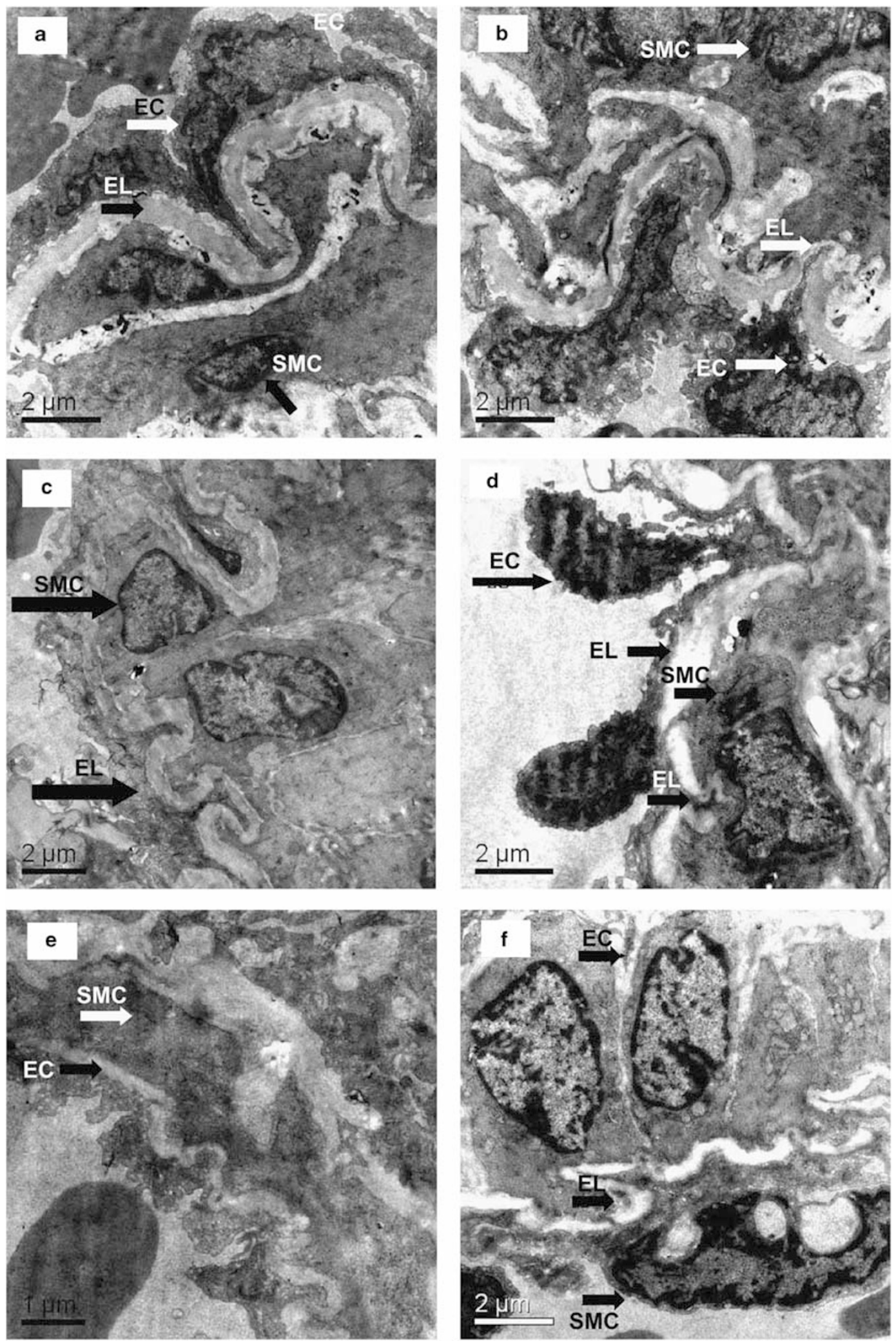

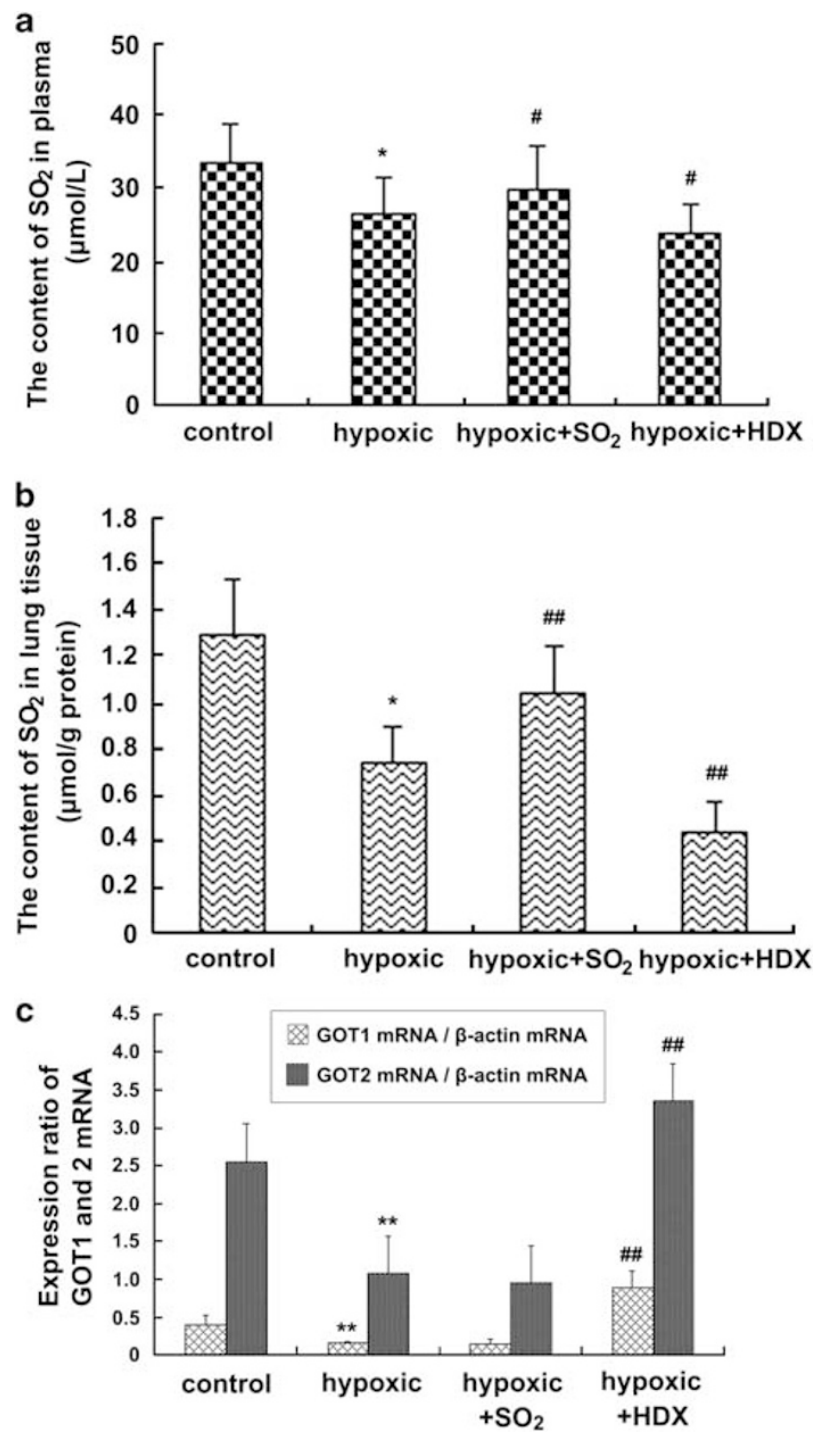

Figure 5 The content of sulfur dioxide $\left(\mathrm{SO}_{2}\right)$ in plasma (a) and lung tissue (b) (mean \pm s.d., IU/l, $\mu \mathrm{g} / \mathrm{ml}$ ) and expression of glutamate oxaloacetate transaminase-1 (GOT-1) and GOT-2 mRNAs in lung tissue (c) (mean \pm s.d.). ${ }^{*}$ Compared with the control group, $P<0.01,{ }^{* *}$ Compared with the control group, $P<0.05$, "Compared with the hypoxic group, $P<0.05$; \#\#Compared with the hypoxic group, $P<0.01$.

\section{Raf-1 and MEK-1 Expressions in Lung Tissue Using Western Blotting}

Compared with the control group, the expressions of Raf- 1 $(P<0.01)$ and MEK-1 $(P<0.05)$ proteins in hypoxic rats obviously rose. However, compared with the hypoxic group, the expressions of Raf- 1 and MEK-1 proteins of rats in the hypoxic $+\mathrm{SO}_{2}$ group decreased $(P<0.05) . \mathrm{SO}_{2}$ donor did not alter the expressions of Raf- 1 and MEK-1 proteins under normoxia $(P>0.05)$. But Raf-1 $(P<0.01)$ and MEK-1 $(P<0.05)$ proteins increased significantly under normoxia with treatment of HDX (Figures 7 and 8).

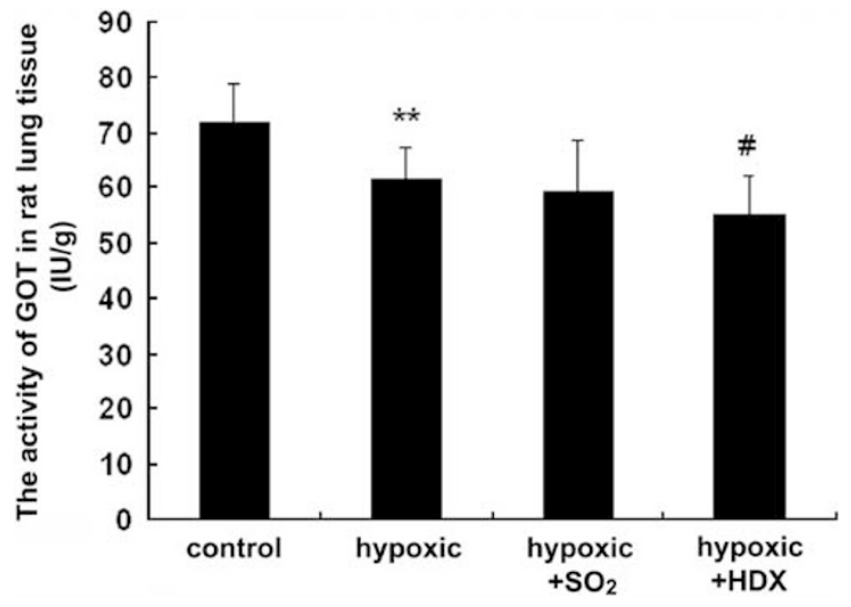

Figure 6 The activity of GOT in rats lung tissue (IU/g, mean \pm s.d.). ${ }^{* * P}<0.01$ compared with control group. ${ }^{\#} P<0.05$ compared with hypoxic group. GOT: glutamate oxaloacetate transaminase.

\section{Expression of p-ERK/ERK in Lung Tissue Using Western Blotting}

Compared with the control group, the expression of the pERK/ERK ratio in the hypoxic rats clearly increased $(P<0.01)$. Compared with the hypoxic group, the expression of the p-ERK/ERK ratio in the rats of the hypoxic $+\mathrm{SO}_{2}$ group decreased $(P<0.05)$. The $\mathrm{SO}_{2}$ donor did not alter the expression of the p-ERK/ERK ratio under normoxia $(P>0.05)$. HDX, an inhibitor of endogenous production of $\mathrm{SO}_{2}$, significantly increased the ratio of $\mathrm{p}$-ERK/ERK protein under normoxia $(P<0.01$; Figure 9$)$.

\section{Expression of Pre-Collagen I and III mRNAs in Lung Tissue}

The expressions of pre-collagen I and III mRNAs in the lung tissue of rats in the hypoxic group were both stronger than those in the control group (both $P<0.01$ ). In the hypoxic $+\mathrm{SO}_{2}$ group, the expressions of both pre-collagen I and III decreased when compared with the hypoxic group (both $P<0.01$ ). However, when treated with HDX, the rats showed increased expressions of pre-collagen I and III mRNAs in the lung tissue of the hypoxic rats (both $P<0.01$ ). They did not change in the control $+\mathrm{SO}_{2}$ group or the control + HDX group (both $P>0.05$ ). The results are shown in Table 3.

Content of Collagen I and III in Lung Tissue Using ELISA The amount of collagen I and III in the hypoxic rats tested using ELISA markedly increased (all $P<0.01$ ) when compared with the control group. For the rats in the hypoxic $+\mathrm{SO}_{2}$ group, the amount of collagen I and III decreased as compared with the hypoxic group $(P<0.01$ and $P<0.05)$. It 
Table 2 Proliferation index (PI) in the smooth muscle cells of pulmonary arteries in lung tissue (mean \pm s.d.)

\begin{tabular}{|c|c|c|c|c|}
\hline \multirow[t]{2}{*}{ Groups } & \multirow[t]{2}{*}{$N$} & \multicolumn{3}{|c|}{ Proliferation index } \\
\hline & & Small artery & Median artery & Large artery \\
\hline Control group & 8 & $3.72 \pm 0.47$ & $4.01 \pm 1.53$ & $4.94 \pm 1.29$ \\
\hline Hypoxic group & 8 & $18.72 \pm 3.97^{\mathrm{a}}$ & $21.53 \pm 6.37^{\mathrm{a}}$ & $21.79 \pm 3.47^{\mathrm{a}}$ \\
\hline Control $+\mathrm{SO}_{2}$ group & 8 & $4.06 \pm 0.25$ & $4.65 \pm 0.49$ & $5.03 \pm 1.14$ \\
\hline Control+HDX group & 8 & $10.23 \pm 2.21^{\mathrm{a}}$ & $12.46 \pm 3.63^{\mathrm{a}}$ & $15.14 \pm 4.31^{\mathrm{a}}$ \\
\hline Hypoxic $+\mathrm{SO}_{2}$ group & 8 & $12.11 \pm 3.42^{b}$ & $15.72 \pm 4.67^{b}$ & $17.38 \pm 4.26^{\mathrm{b}}$ \\
\hline Hypoxic+HDX group & 8 & $23.91 \pm 3.77^{c}$ & $31.09 \pm 5.01^{b}$ & $27.02 \pm 6.51^{b}$ \\
\hline
\end{tabular}

${ }^{\mathrm{a}}$ Compared with control group, $P<0.01$.

${ }^{\mathrm{b}}$ Compared with hypoxic group, $P<0.01$.

${ }^{\mathrm{C} C o m p a r e d}$ with hypoxic group, $P<0.05$.
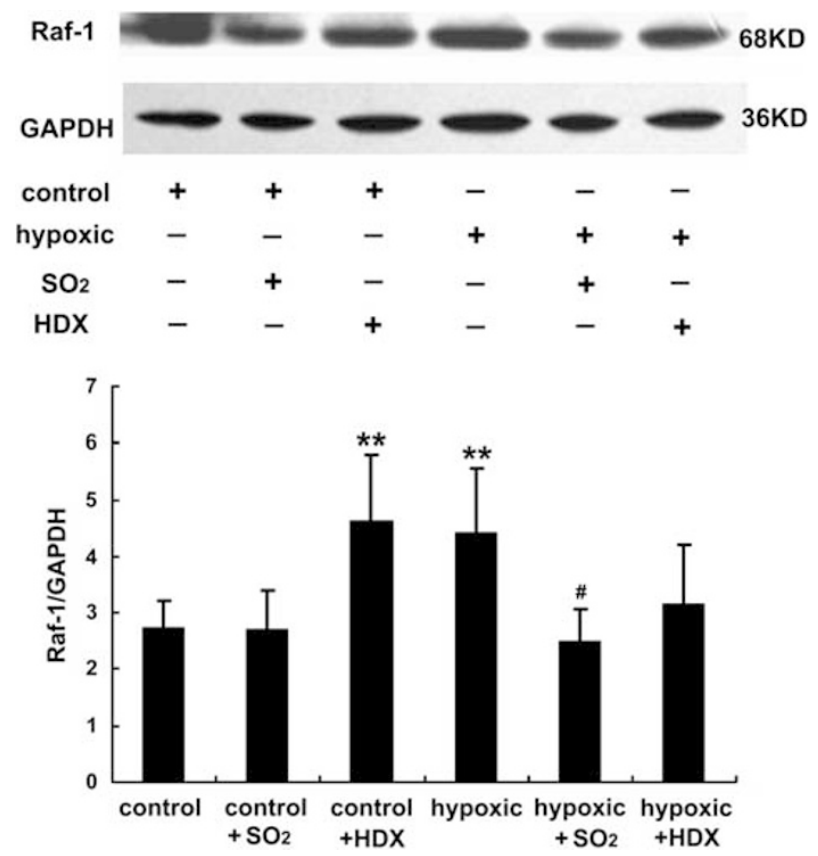

Figure 7 The expression of Raf- 1 in rat lung tissue (mean \pm s.d.). ${ }^{* *} P<0.01$ compared with control group. ${ }^{\#} P<0.05$ compared with hypoxic group.

increased in the rats of the hypoxia + HDX group (all $P<0.05)$ in comparison with the hypoxic rats (Table 3 ).

\section{Expression of Collagen I and III mRNAs in the Smooth Muscle Cells of Pulmonary Arteries by In Situ Hybridization}

The expressions of collagen I and III in small and mediumsized muscularized arteries were much stronger in the rats of the hypoxia group than in the rats of the control group. For rats in the hypoxic $+\mathrm{SO}_{2}$ group, the expressions of collagen I and III in small muscularized arteries and medium-sized

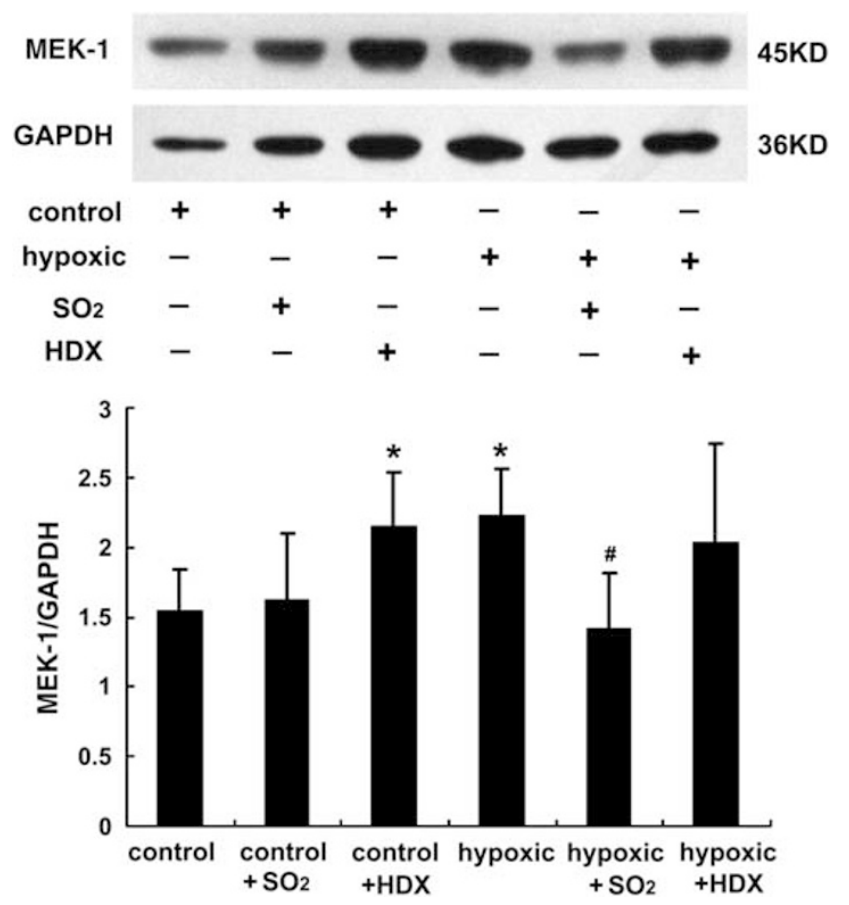

Figure 8 The expression of MEK- 1 in rat lung tissue (mean \pm s.d.). ${ }^{*} P<0.05$ compared with control group. ${ }^{\#} P<0.05$ compared with hypoxic group.
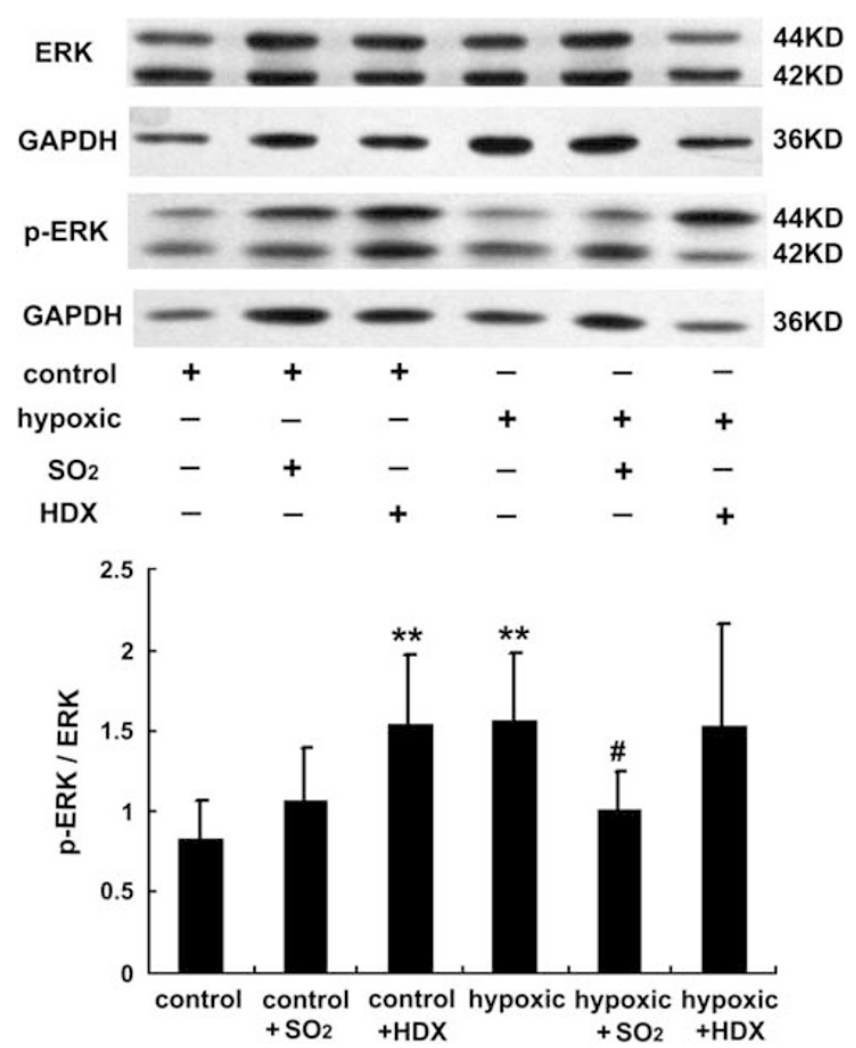

Figure 9 The expression of $p$-ERK/ERK in rat lung tissue (mean \pm s.d.). ${ }^{* *} P<0.01$ compared with control group. ${ }^{\#} P<0.05$ compared with hypoxic group. 
Table 3 Expression of pre-collagen I and III mRNAs in lung tissue (mean \pm s.d.) and the amount of collagen I and III in lung tissue determined using ELISA method (mean \pm s.d., $\mu \mathrm{g} / \mathrm{g}$ )

\begin{tabular}{|c|c|c|c|c|c|}
\hline Groups & $N$ & $\begin{array}{l}\text { Pre-collagen I mRNA/ } \\
\boldsymbol{\beta} \text {-actin mRNA ratio }\end{array}$ & $\begin{array}{l}\text { Pre-collagen III mRNA/ } \\
\boldsymbol{\beta} \text {-actin mRNA ratio }\end{array}$ & $\begin{array}{l}\text { Collagen I } \\
(\mu \mathrm{g} / \mathrm{g})\end{array}$ & $\begin{array}{c}\text { Collagen III } \\
(\mu \mathrm{g} / \mathrm{g})\end{array}$ \\
\hline Control group & 8 & $0.35 \pm 0.07$ & $0.55 \pm 0.10$ & $1.06 \pm 0.15$ & $1.20 \pm 0.13$ \\
\hline Hypoxic group & 8 & $0.65 \pm 0.13^{\mathrm{a}}$ & $0.85 \pm 0.16^{a}$ & $1.56 \pm 0.08^{\mathrm{b}}$ & $1.60 \pm 0.11^{b}$ \\
\hline Control $+\mathrm{SO}_{2}$ group & 8 & $0.43 \pm 0.09$ & $0.68 \pm 0.22$ & $0.97 \pm 0.07$ & $1.18 \pm 0.21$ \\
\hline Control+HDX group & 8 & $0.43 \pm 0.10$ & $0.65 \pm 0.18$ & $1.05 \pm 0.10$ & $1.23 \pm 0.15$ \\
\hline Hypoxic+HDX group & 8 & $0.79 \pm 0.12^{c}$ & $0.99 \pm 0.17^{c}$ & $1.73 \pm 0.23^{c}$ & $1.77 \pm 0.21^{c}$ \\
\hline
\end{tabular}

${ }^{\mathrm{a}}$ Compared with control group, $P<0.01$.

${ }^{\mathrm{b}}$ Compared with control group, $P<0.05$.

${ }^{\mathrm{c}}$ Compared with hypoxic group, $P<0.01$.

${ }^{\mathrm{d}}$ Compared with hypoxic group, $P<0.05$.

Table 4 Collagen I and III mRNA expressions by smooth muscle cells of pulmonary arteries using in situ hybridization (mean \pm s.d.)

\begin{tabular}{|c|c|c|c|c|c|}
\hline \multirow[t]{2}{*}{ Groups } & \multirow[t]{2}{*}{$N$} & \multicolumn{2}{|c|}{ Expression of collagen I } & \multicolumn{2}{|c|}{ Expression of collagen III } \\
\hline & & Small artery & Median artery & Small artery & Median artery \\
\hline Control group & 8 & $0.20 \pm 0.03$ & $0.21 \pm 0.01$ & $0.21 \pm 0.006$ & $0.22 \pm 0.005$ \\
\hline Hypoxic group & 8 & $0.30 \pm 0.02^{\mathrm{a}}$ & $0.32 \pm 0.009^{\mathrm{a}}$ & $0.30 \pm 0.01^{\mathrm{a}}$ & $0.31 \pm 0.005^{\mathrm{a}}$ \\
\hline Hypoxic $+\mathrm{SO}_{2}$ group & 8 & $0.26 \pm 0.003^{b}$ & $0.26 \pm 0.005^{b}$ & $0.25 \pm 0.04^{b}$ & $0.26 \pm 0.005^{b}$ \\
\hline
\end{tabular}

${ }^{\mathrm{a}}$ Compared with control group, $P<0.05$.

${ }^{\mathrm{b}}$ Compared with hypoxic group, $P<0.05$.

muscularized arteries were weaker than in the hypoxic rats. HDX increased collagen-I and collagen-III mRNA signals in rats of the hypoxia + HDX group as compared with hypoxic rats (small arteries all $P<0.01$; medium-sized arteries, all $P<0.01$; Table 4).

\section{Expressions of MMP-13 mRNA and TIMP-1 mRNA in Smooth Muscle Cells of Pulmonary Arteries}

Expressions of MMP-13 mRNA and TIMP-1 mRNA in smooth muscle cells of small and medium-sized pulmonary arteries were significantly higher in the hypoxia group than in the control group $(P<0.01)$, but the ratio of TIMP-1 mRNA/ MMP-13 mRNA in small and medium-sized pulmonary muscularized arteries decreased significantly $(P<0.01)$ in the hypoxic group. In the hypoxic $+\mathrm{SO}_{2}$ group, the expression of MMP-13 mRNA in small and medium-sized pulmonary arteries increased $(P<0.01)$, whereas TIMP-1 mRNA expression was reduced $(P<0.01)$; MMP-13 mRNA/TIMP-1 mRNA ratio was significantly higher $(P<0.01)$ compared with the hypoxia group. In the hypoxia + HDX group, expression of MMP-13 mRNA in small and medium-sized pulmonary arteries was further reduced $(P<0.01)$, whereas TIMP-1 mRNA expression was further increased $(P<0.01)$. The MMP-13 mRNA/TIMP-1 mRNA ratio, however, was significantly lower $(P<0.01)$ than the ratio in the hypoxia group (Table 5).

\section{Expression of NF- $\kappa$ B in the Endothelial Cells of Pulmonary Arteries}

Compared with the control group, the expression of NF- $\kappa \mathrm{B}$ in the small pulmonary arteries of hypoxic rats rose significantly $(P<0.01)$. Compared with the hypoxic group, NF$\kappa \mathrm{B}$ expression decreased in the hypoxic $+\mathrm{SO}_{2}$ group $(P<0.01)$ but significantly increased in the hypoxic + HDX group $(P<0.01$; Figure 10$)$.

Expression of NF- $\kappa \mathrm{B}$ in the medium-sized pulmonary arteries of hypoxic rats rose significantly $(P<0.01)$ compared with such expression in the control group. Compared with the hypoxic group, however, the expression of NF- $\kappa \mathrm{B}$ in the pulmonary arteries of rats in the hypoxic $+\mathrm{SO}_{2}$ group 
Table 5 The ratio of metalloproteinase-13 (MMP-13) mRNA to metalloproteinease-1 (TIMP-1) mRNA in small and median pulmonary artery (mean \pm s.d.)

\begin{tabular}{|c|c|c|c|}
\hline \multirow[t]{2}{*}{ Groups } & \multirow[t]{2}{*}{$N$} & \multicolumn{2}{|c|}{ MMP-13mRNA/TIMP-1mRNA ratio } \\
\hline & & Small artery & Median artery \\
\hline Control group & 8 & $0.95 \pm 0.038$ & $0.93 \pm 0.036$ \\
\hline Hypoxic group & 8 & $0.88 \pm 0.032^{a}$ & $0.89 \pm 0.025^{b}$ \\
\hline Hypoxic $+\mathrm{SO}_{2}$ group & 8 & $1.13 \pm 0.079^{c}$ & $1.16 \pm 0.049^{c}$ \\
\hline Hypoxic+HDX group & 8 & $0.75 \pm 0.025^{c}$ & $0.76 \pm 0.028^{c}$ \\
\hline
\end{tabular}

${ }^{\mathrm{a}}$ Compared with control group, $P<0.01$.

${ }^{\mathrm{b}}$ Compared with control group, $P<0.05$.

${ }^{c}$ Compared with hypoxic group, $P<0.05$.
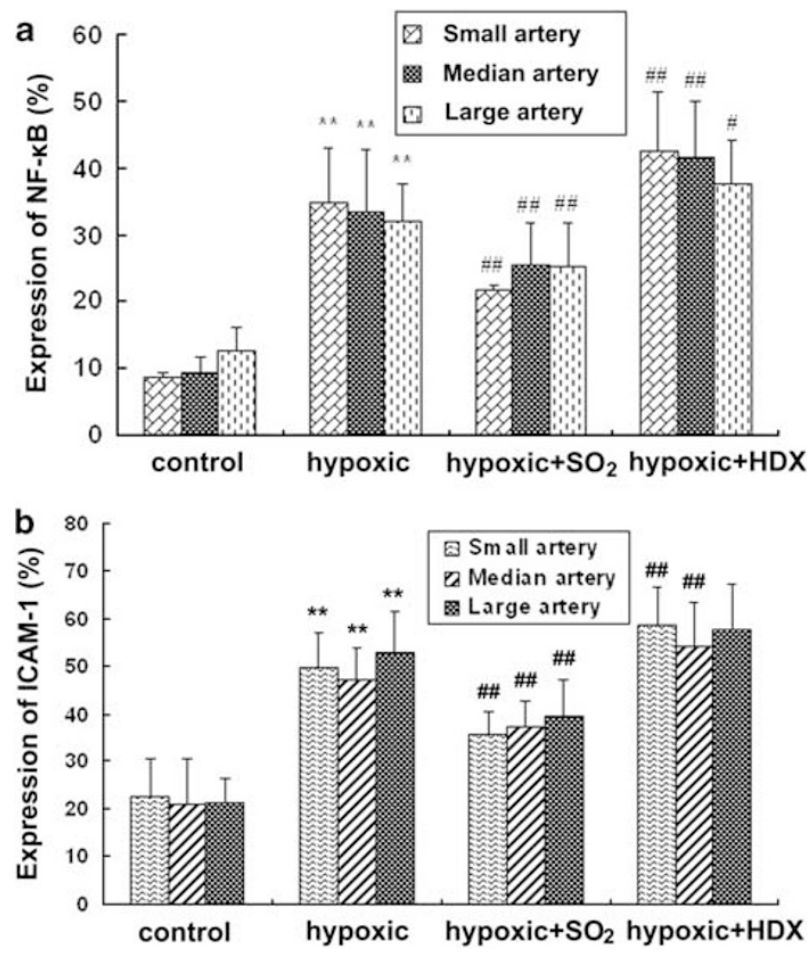

Figure 10 Expression of the percentage of nuclear factor- $\kappa \mathrm{B}(\mathrm{NF}-\kappa \mathrm{B})(\mathbf{a})$ and intercellular adhesion molecule-1 (ICAM-1) (b) in the endothelial cells of pulmonary arteries (mean \pm s.d.). ${ }^{* *}$ Compared with the control group, $P<0.01$. "\# Compared with the hypoxic group, $P<0.01$. "Compared with the hypoxic group, $P<0.05$.

decreased significantly $(P<0.01)$, but clearly increased in the hypoxic + HDX group $(P<0.01$; Figure 10$)$.

Changes in the expression of NF- $\kappa \mathrm{B}$ in the large pulmonary arteries of rats in the hypoxic group rose significantly $(P<0.01)$ compared with such expression in the control group. Compared with the hypoxic group, the expression of $\mathrm{NF}-\kappa \mathrm{B}$ in the pulmonary arteries of rats in the hypoxic $+\mathrm{SO}_{2}$
Table 6 Concentration of ET-1 in plasma (mean \pm s.d., $\mathrm{pg} / \mathrm{ml}$ ) and the expression of ET-1 mRNA in lung tissue (mean \pm s.d.)

\begin{tabular}{lccc}
\hline Groups & $N$ & $\begin{array}{c}\text { Concentration of } \\
\text { ET-1 in plasma }(\mathrm{pg} / \mathrm{ml})\end{array}$ & $\begin{array}{c}\text { ET-1mRNA/ } \\
\boldsymbol{\beta} \text {-actin mRNA }\end{array}$ \\
\hline Control group & 8 & $115.33 \pm 20.12$ & $0.57 \pm 0.12$ \\
Hypoxic group & 8 & $152.89 \pm 32.37^{\mathrm{a}}$ & $0.82 \pm 0.10^{\mathrm{b}}$ \\
Control+SO 2 group & 8 & $154.45 \pm 30.03^{\mathrm{b}}$ & $0.75 \pm 0.07^{\mathrm{b}}$ \\
Control+HDX group & 8 & $168.56 \pm 42.39^{\mathrm{b}}$ & $0.54 \pm 0.10$ \\
Hypoxic+$+\mathrm{SO}_{2}$ group & 8 & $124.48 \pm 19.19^{\mathrm{c}}$ & $0.67 \pm 0.08^{\mathrm{c}}$ \\
Hypoxic+HDX group & 8 & $181.12 \pm 22.01^{\mathrm{c}}$ & $0.99 \pm 0.12^{\mathrm{c}}$
\end{tabular}

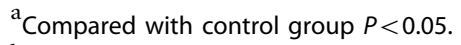

${ }^{\mathrm{b}}$ Compared with control group $P<0.01$.

${ }^{\mathrm{C} C o m p a r e d}$ with hypoxic group, $P<0.05$.

group decreased $(P<0.01)$, but clearly rose in the hypoxic + HDX group $(P<0.05$; Figure 10$)$.

\section{Expression of ICAM-1 in the Endothelial Cells of Pulmonary Arteries}

Expression of ICAM-1 rose significantly in the small pulmonary arteries $(P<0.01)$, medium-sized arteries $(P<0.01)$, and large arteries $(P<0.01)$ of hypoxic rats, as compared with the respective arteries in the controls; expression was lowered significantly in the small pulmonary arteries $(P<0.01)$, medium-sized arteries $(P<0.01)$, and large arteries $(P<0.01)$ of rats in the hypoxic $+\mathrm{SO}_{2}$ group, but in the hypoxic + HDX group, expression rose in small arteries $(P<0.01)$ and medium-sized arteries $(P<0.01$; Figure 10$)$.

\section{Concentration of ET-1 in Plasma and Expression of ET-1 mRNA in Lung Tissue}

The plasma content and expression in lung tissue of ET- 1 are shown in Table 6. The ET-1 plasma content for hypoxic rats was higher in the hypoxic group than in the control group $(P<0.05) . \mathrm{SO}_{2}$ donor decreased $(P<0.05)$, but HDX increased $(P<0.05)$ the content of ET-1 in the plasma of rats under hypoxia. ET-1 mRNA in the lung tissues of hypoxic rats rose significantly in comparison with those in the control group $(P<0.01) . \mathrm{SO}_{2}$ donor decreased $(P<0.05)$ whereas HDX increased $(P<0.05)$ the expression of ET-1 mRNA in the lung tissues of hypoxic rats (Table 6).

\section{DISCUSSION}

Hypoxic pulmonary hypertension complicates the clinical course of many important pulmonary and cardiac diseases. Endogenous gasotransmitters, such as $\mathrm{NO}, \mathrm{CO}$, and $\mathrm{H}_{2} \mathrm{~S}$, have been shown to have regulatory roles in the development of HPVSR by inhibiting the proliferation of smooth muscle cells and abnormal deposition of collagen, and facilitating the apoptosis of PASMCs. ${ }^{15-20}$ 
Recent research indicates that $\mathrm{SO}_{2}$ could be produced endogenously in vessels ${ }^{11}$ and regulate both blood pressure and inflammatory response, which suggests that $\mathrm{SO}_{2}$ may be involved in the pathogenesis of various cardiovascular diseases. $\mathrm{SO}_{2}$ and its hydrated form, sulfite/bisulfite, were generated through the normal processing of sulfur-containing amino acids such as L-cysteine. L-cysteine is first oxidized through cysteine dioxygenase into L-cysteinesulfinate, and the latter is metabolized through two competing pathways. As an analog of L-aspartate, cysteinesulfinate is a substrate of GOT; $\beta$-sulfinylpyruvate, the putative product, decomposes spontaneously to pyruvate and $\mathrm{SO}_{2} \cdot{ }^{21}$ Thus, GOT could be a key enzyme in controlling the endogenous production of $\mathrm{SO}_{2}$. Exogenous and endogenous $\mathrm{SO}_{2}$ was shown to exist in plasma and tissue in the form of sulfite-bimane $\left(\mathrm{SO}_{3}^{2-}\right.$ and $\mathrm{HSO}_{3}^{-}$), implicating that the level of sulfite-bimane may represent $\mathrm{SO}_{2}$ content.

The PAP and micro- and ultra-structural findings in the hypoxic group showed that rats exposed to hypoxia for 3 weeks showed significant pulmonary hypertension and vascular structural remodeling. Surprisingly, the $\mathrm{SO}_{2}$ content in plasma and lung tissues and the GOT $1 / \beta$-actin mRNA to GOT2 $/ \beta$-actin mRNA ratio in lung tissues decreased under the hypoxic condition. This indicates a downregulated $\mathrm{SO}_{2}$ /glutamate oxaloacetate transaminase pathway in the development of hypoxic pulmonary hypertension.

To determine whether the downregulated $\mathrm{SO}_{2}$ /glutamate oxaloacetate transaminase pathway was involved in the development of hypoxic pulmonary hypertension, a hypoxic $+\mathrm{SO}_{2}$ group and hypoxic $+\mathrm{HDX}$ group were included in the experiment design. Human serum contains sulfite (a known $\mathrm{SO}_{2}$ derivative) at a concentration of $0-10 \mu \mathrm{M}$. Thus, $\mathrm{Na}_{2} \mathrm{SO}_{3}$ and $\mathrm{NaHSO}_{3}$ were used as donors for $\mathrm{SO}_{2}$ in the ratio $0.54: 0.18(\mathrm{mmol} / \mathrm{kg})$ in rats of the hypoxic $+\mathrm{SO}_{2}$ group, and HDX was used as a GOT inhibitor at $3.7 \mathrm{mg} / \mathrm{kg}$ each day ${ }^{11}$ in rats of the hypoxic + HDX group.

Under identical hypoxic conditions, rats of the hypoxic $+\mathrm{SO}_{2}$ group showed increased $\mathrm{SO}_{2}$ content in plasma and lung tissues, whereas the mean PAP of hypoxic rats clearly decreased. Thus, it is possible that $\mathrm{SO}_{2}$ donor could lower the increased PAP and reverse pulmonary vascular remodeling, as showed by the micro- and ultra-structural observations in association with increases in $\mathrm{SO}_{2}$ content in plasma. Under hypoxic conditions and after treatment with $\mathrm{HDX}, \mathrm{SO}_{2}$ content in plasma and lung tissues decreased and pulmonary hypertension and pulmonary vascular structural remodeling worsened greatly. Such results suggested that the downregulated $\mathrm{SO}_{2}$ /glutamate oxaloacetate transaminase pathway was involved in the development of HPVSR.

The results showed that $\mathrm{SO}_{2}$ might inhibit the proliferation and accelerate the apoptosis of smooth muscle cells and reduce hyperplasia of pulmonary arteries. Proliferation of PASMCs is a pivotal component for the development of HPVSR. We calculated the percentage of PASMCs expressing PCNA-positive signals in all PASMCs. Chronic hypoxia significantly increased the PI of PASMCs in small, medium-sized, and large pulmonary arteries. $\mathrm{SO}_{2}$ significantly decreased the PI of PASMCs in pulmonary arteries as compared with the hypoxia group without $\mathrm{SO}_{2}$ treatment, which suggests that $\mathrm{SO}_{2}$ could affect cell-cycle processes and reduce the proliferative response of vascular smooth muscle cells induced by hypoxia. The mechanisms by which $\mathrm{SO}_{2}$ inhibits proliferation are unclear. The mitogenactivated protein kinase (MAPK) pathway is a typical cellsignaling pathway that advances cellular proliferation. Raf-1, MEK-1, and p-ERK/ERK are three main components arranged in order in the MAPK pathway. The present study examined the expressions of Raf-1, MEK-1, and p-ERK/ERK in the lung tissues of rats under hypoxia. $\mathrm{SO}_{2}$ may inhibit the expression of Raf-1 protein, which is upstream of MEK-1. It was also found that the stimulation of phosphorylation of ERK by MEK-1 was also downregulated, resulting in a decrease in the p-ERK/ERK ratio by $35.8 \%$. These results suggested that $\mathrm{SO}_{2}$ inhibited the proliferation of vascular smooth muscle cells and HPVSR, likely through the MAPK signaling pathway (Figure 11). The mechanism of HPVSR is a very complex pathological process that requires further research. ${ }^{22}$

ET-1 is known to be an effective vasoconstrictor. The plasma concentration of ET-1 and lung tissue ET-1 mRNA were upregulated in the hypoxic group, decreased in the
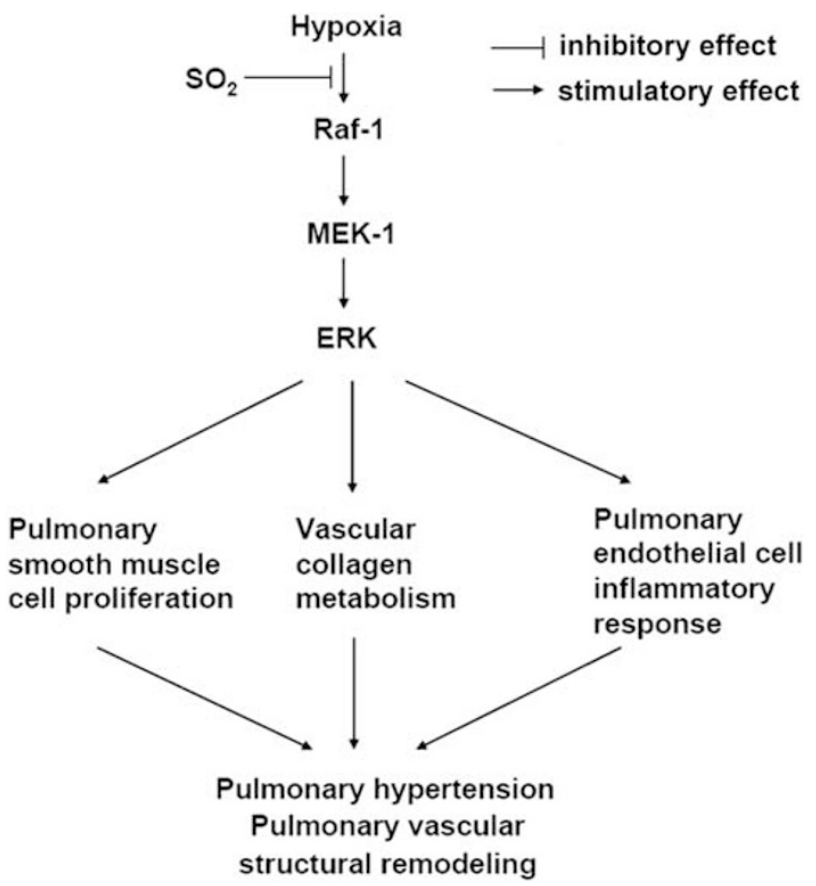

Figure 11 The diagram of possible mechanisms by which sulfur dioxide regulates pulmonary hypertension. $\mathrm{SO}_{2}$ inhibits the expression of Raf-1 protein, which was upstream of MEK-1, resulting in a decrease in p-ERK/ ERK. The diagram suggests that $\mathrm{SO}_{2}$ inhibits the proliferation of vascular smooth muscle cells and HPVSR, probably through the MAPK signaling pathway. 
hypoxic $+\mathrm{SO}_{2}$ group, and significantly increased in the hypoxic $+\mathrm{HDX}$ group. These results suggest that $\mathrm{SO}_{2}$ regulates the transcription of ET-1 mRNA, which may be associated with the regulation of the proliferation and collagen remodeling in pulmonary arteries induced by hypoxia. ${ }^{23}$

Studies have shown that the extracellular matrix (ECM) contributes greatly to pulmonary vascular structural remodeling. Changes in the absolute or relative contents of pre-collagen I and III would probably result in structural remodeling. Our studies showed that $\mathrm{H}_{2} \mathrm{~S}$ reduced the collagen remodeling of pulmonary arteries under hypoxia. ${ }^{24}$ We found that the expression of pre-collagen I and III mRNAs increased in the hypoxic group, clearly decreased in the hypoxic $+\mathrm{SO}_{2}$ group, but increased even more in the hypoxic + HDX group. The results were similar to those evaluated using in situ hybridization and ELISA. This suggests that $\mathrm{SO}_{2}$ has an important role in the regulation of collagen remodeling induced by hypoxia. It is believed that MMPs are important enzymes for degrading the macromolecular proteins in the ECM, and are closely related to the degradation and accumulation of ECM, and the migration and proliferation of vascular smooth muscle cells. The main function of MMP-1 and MMP-13 is to stimulate the degradation of collagen. ${ }^{25}$ TIMP-1 inhibits this degradation ability of MMPs. MMP-1 and TIMP-1 regulate the degradation of pulmonary collagen. Not only can TIMPs inhibit activated MMPs, but they can also obstruct and delay the conversion of prototype MMPs to activated forms. ${ }^{26}$ This study revealed that the expression of MMP-13 mRNA and TIMP-1 mRNA increased in small and medium-sized pulmonary arteries of rats in the hypoxic group in relation to those of the control rats, whereas the MMP-13 mRNA/TIMP1 mRNA ratio decreased. Compared with those of the hypoxic group, the expressions of MMP-13 mRNA in small and medium-sized pulmonary arteries in the hypoxic $+\mathrm{SO}_{2}$ group increased, whereas TIMP-1 mRNA decreased and the ratio of MMP-13 mRNA/TIMP-1 mRNA increased. In the hypoxic + HDX group, the expression of MMP-13 mRNA in small and medium-sized pulmonary arteries decreased further, whereas TIMP-1 mRNA further increased, in comparison with the hypoxic group. The ratio of MMP-13 mRNA/ TIMP-1 mRNA also decreased significantly as compared with the ratio in the hypoxic group. The above results showed that the degradation of extracellular collagen decreased in hypoxic rats. Supplementation with exogenous $\mathrm{SO}_{2}$ promoted the degradation of extracellular collagen, but the inhibition of endogenous $\mathrm{SO}_{2}$ increased collagen production. This suggested that by promoting collagen degradation, $\mathrm{SO}_{2}$ inhibited abnormal collagen accumulation in the pulmonary artery under hypoxic conditions.

Inflammation is important in the pathogenesis of vascular injury caused by hypertension. ${ }^{27}$ In this study, ICAM-1 and $\mathrm{NF}-\kappa \mathrm{B}$ levels were clearly increased in the hypoxic groups, but $\mathrm{SO}_{2}$ could reduce the expression of ICAM- 1 and NF- $\kappa \mathrm{B}$ in the hypoxic $+\mathrm{SO}_{2}$ group compared with the hypoxia group alone, whereas HDX could significantly augment them in hypoxic rats. NF- $\kappa \mathrm{B}$ is considered to be a type of nuclear transfer regulating factor. ${ }^{28}$ In normal cells, NF- $\kappa \mathrm{B}$ binding to inhibitor of $\kappa \mathrm{B}(\mathrm{I} \kappa \mathrm{B})$ is expressed in the cytoplasm. ${ }^{29}$ When stimulated by injury factors, such as inflammation, NF- $\kappa \mathrm{B}$ separates from $\mathrm{I} \kappa \mathrm{B}$ in the cytoplasm and enters the nucleolus, in which it then stimulates inflammatory factors, such as ICAM-1, monocyte chemotactic protein-1 (MCP-1), and interleukin-8 (IL-8).$^{30}$ Our data suggest that $\mathrm{SO}_{2}$ may have a role in regulating the inflammatory response, but this mechanism needs further research.

In conclusion, we showed that $\mathrm{SO}_{2}$ markedly inhibited the PAMSC proliferation, probably by downregulating Raf-1, MEK-1, and phosphorylating ERK under hypoxia. It is likely that the downregulated $\mathrm{SO}_{2}$ /glutamate oxaloacetate transaminase pathway is involved in the mechanisms responsible for pulmonary hypertension and pulmonary vascular structural remodeling.

\section{ACKNOWLEDGEMENTS}

This work was supported by the Foundation of the Ministry of Education, People's Republic of China (20070001702, 307001), the National Natural Science Foundation of China (30630031, 30821001, 30801251), and the Major Basic Research Development Program of People's Republic of China (2006CB503807) and Beijing Natural Science Foundation (7072082).

\section{DISCLOSURE/CONFLICT OF INTEREST}

The authors declare no conflict of interest.

1. Pepke-Zaba J, Higenbottam TW, Dinh-Xuan AT, et al. Inhaled nitric oxide as a cause of selective pulmonary vasodilatation in pulmonary hypertension. Lancet 1991;338:1173-1174.

2. Frostell C, Fratacci MD, Wain JC, et al. Inhaled nitric oxide. A selective pulmonary vasodilator reversing hypoxic pulmonary vasoconstriction. Circulation 1991;83:2038-2047.

3. Morita T, Mitsialis SA, Koike $\mathrm{H}$, et al. Carbon monoxide controls the proliferation of hypoxic vascular smooth muscle cells. J Biol Chem 1997;272:32804-32809.

4. Rodgers PA, Vreman HJ, Dennery PA, et al. Sources of carbon monoxide (CO) in biological systems and applications of $\mathrm{CO}$ detection technologies. Semin Perinatol 1994;18:2-10.

5. Du JB, Chen XB, Geng B, et al. Hydrogen sulfide as a messenger molecule in cardiovascular system. J Beijing Med Univ 2002;34:187.

6. Hui $Y$, Du J, Tang $C$, et al. Changes in arterial hydrogen sulfide $\left(\mathrm{H}_{2} \mathrm{~S}\right)$ content during septic shock and endotoxin shock in rats. J Infect 2003;47:155-160.

7. Durante W. Carbon monoxide and bile pigments: surprising mediators of vascular function. Vasc Med 2002;7:195-202.

8. Hampl V, Herget J. Role of nitric oxide in the pathogenesis of chronic pulmonary hypertension. Physiol Rev 2000;80:1337-1372.

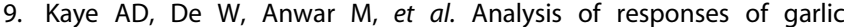
derivatives in the pulmonary vascular bed of the rat. J Appl Physiol 2000;89:353-358.

10. Meng Z, Geng H, Bai J, et al. Blood pressure of rats lowered by sulfur dioxide and its derivatives. Inhal Toxicol 2003;15:951-959.

11. Shu-xu DU, Hong-fang JIN, Ding-fang BU, et al. Endogenously generated sulfur dioxide and its vasorelaxant effect in rats. Acta Pharmacol Sin 2008;29:923-930.

12. Stipanuk MH, Dominy Jr JE, Lee J-I, et al. Mammalian cysteine metabolism: new insights into regulation of cysteine metabolism. J Nutr 2002;136:1652-1659.

13. Ubuka T, Yuasa S, Ohta J, et al. Formation of sulfate from L-cysteine in rat liver mitochondria. Acta Med 1990;44:55-64. 
14. Griffith OW. Cysteine sulfinate metabolism. J Bio Chem 1983;258: 1591-1598.

15. Zhang CY, Du JB, Bu DF, et al. The regulatory effect of hydrogen sulfide on hypoxic pulmonary hypertension in rats. Biochem Biophys Res Commun 2003;302:810-881.

16. Jeffery TK, Morrel NW. Molecular and cellular basis of pulmonary vascular remodeling in pulmonary hypertension. Prog Cardiovasc Dis 2002;45:173-202.

17. Hideki $M$, Hidekazu I, Shin $Y$, et al. Increased levels of serum sulfite in patients with acute pneumonia. Shock 2004;21:99-102.

18. Qi JG, Du JB, Wang L. Alleviation of hypoxic pulmonary vascular structural remodeling by l-arginine. Chin Med J 2001;38:114-117.

19. Shi $Y$, Du JB, Gong LM, et al. The regulating effect of heme oxygenase/carbon monoxide on hypoxic pulmonary vascular structural remodeling. Biochem Biophys Res Commun 2003;306: 523-529.

20. Zhao W, Zhang J, Lu Y, et al. The vasorelaxant effect of $\mathrm{H}_{2} \mathrm{~S}$ as a novel endogenous gaseous $\mathrm{K}_{\mathrm{ATP}}$ channel opener. EMBO J 2001;20:6008-6016.

21. Ji AJ, Savon SR, Jacobsen DW. Determination of total serum sulfite by HPLC with fluorescence detection. Clin Chem 1995;41:897-903.

22. Yamaguchi M, Hayashi $Y$, Hirose $F$, et al. Molecular cloning and structural analysis of mouse gene and pseudogenes for proliferating cell nuclear antigen. Nucleic Acids Res 1991;19:2403-2410.
23. Cai $\mathrm{C}, \mathrm{Xu} J$, Zhang $\mathrm{M}$, et al. Prior $\mathrm{SO}_{2}$ exposure promotes airway inflammation and subepithelial fibrosis following repeated ovalbumin challenge. Clin Exp Allergy 2008;38:1680-1687.

24. Zhang CY, Du JB, Yan H, et al. Effect of a new gasotransmitter, hydrogen sulfide, on collagen remodeling of pulmonary artery under hypoxia. Zhonghua Jie He He Hu Xi Za Zhi 2005;28:448-452.

25. Zaidi SH, You XM, Ciura $S$, et al. Overexpression of the serine elastase inhibitor elacin protects transgenic mice from hypoxic pulmonary hypertension. Circulation 2002;105:516-521.

26. Twigg SM, Joly AH, Chen MM, et al. Connective tissue growth factor/ IGF-binding protein-related protein-2 is a mediator in the induction of fibronectin by advanced glycosylation end-products in human dermal fibroblasts. Endocrinology 2002;143:1260-1269.

27. Li JJ. Inflammation in hypertension: primary evidence. Chin Med J 2006;119:1215-1221.

28. Siebenlist U, Franzoso G, Brown K. Structure, regulation and function of NF- $\kappa$ B. Annu Rev Cell Biol 1994;10:405-455.

29. Huang $S$, Robison JB, Deguzman $A$, et al. Blockade of nuclear factorkappa $B$, signaling inhibits angiogenesis and tumorigenicity of human ovarian cancer cells by suppressing expression of vascular endothelial growth factor and interleukin 8. Cancer Res 2000;60:5334.

30. Chen FE, Huang DB, Chen YQ, et al. Crystal structure of p50/p65 heterodimer of transcription factor NF- $\kappa \mathrm{B}$ bound to DNA. Nature 1998;391:410-413. 